\title{
Clothing Area Factor for Typical Seasonal Clothing of Infant
}

\section{Yoshihito Kurazumi ${ }^{*}$, Kenta Fukagawa ${ }^{2}$, Tomonori Sakoi ${ }^{3}$, Akie Naito ${ }^{4}$, Reiko Hashimoto5, Emi Kondo ${ }^{6}$, Tadahiro Tsuchikawa ${ }^{7}$}

${ }^{1}$ School of Life Studies, Sugiyama Jogakuen University, Nagoya, Japan

${ }^{2}$ Department of Architecture, Kyushu Sangyo University, Fukuoka, Japan

${ }^{3}$ Department of Advanced Textile and Kansei Engineering, Shinshu University, Ueda, Japan ${ }^{4}$ Institute for Global Leadership, Ochanomizu University, Tokyo, Japan

${ }^{5}$ School of Life Studies, Sugiyama Jogakuen University, Nagoya, Japan

${ }^{6}$ Department of Comprehensive Engineering, Kindai University Technical College, Nabari, Japan

${ }^{7}$ School of Human Science \& Environment, University of Hyogo, Himeji, Japan

Email: *kurazumi@sugiyama-u.ac.jp

How to cite this paper: Kurazumi, Y., Fukagawa, K., Sakoi, T., Naito, A., Hashimoto, R., Kondo, E. and Tsuchikawa, T. (2021) Clothing Area Factor for Typical Seasonal Clothing of Infant. Health, 13, 378-392. https://doi.org/10.4236/health.2021.134031

Received: March 23, 2021

Accepted: April 18, 2021

Published: April 21, 2021

Copyright (c) 2021 by author(s) and Scientific Research Publishing Inc. This work is licensed under the Creative Commons Attribution International License (CC BY 4.0).

http://creativecommons.org/licenses/by/4.0/

\begin{abstract}
It is not ethical to conduct experiments on infants regarding the thermal environment. Therefore, to examine the thermal environment of infants, experiments and simulations using a human body thermal model may be feasible by clarifying the human body coefficient values of infants. When focusing on the heat transfer area of the infant's body coefficient values, the body surface area and solar radiation area factor have only been clarified as the standard. The essential basic data for examining the thermal environment of infants have not been sufficiently obtained. Therefore, the purpose of this study was to determine the clothing area factor for infants' clothing in a typical season. The clothing area factor of infants clothed in summer, mid-season, and winter clothing was measured using a photographic method. The clothing area factor was 1.22, 1.42, and 1.90 for summer, mid-season, and winter clothing, respectively, indicating a significant seasonal difference. It was also found that the clothing area factor was significantly greater for infants than for adults.
\end{abstract}

\section{Keywords}

Clothing Area Factor, Heat Transfer Area, Infant, Season, Thermal Environment

\section{Introduction}

There are two approaches to the evaluation of the thermal environment, that is, whether the boundary surface for consideration of the body heat balance is 
based on the naked or clothed state. When considering the body heat balance based on the clothed state, it is necessary to clarify the surface temperature of the clothing. However, it is difficult to measure the clothing surface temperature accurately because there is an air mass between the body and the woven textile material. In addition, the heat transfer area of the surface of clothing is larger than that of the skin surface, and the heat transfer area of the clothing is affected by the combination of clothing and differences in the way clothing is worn, such as folding and overlapping.

It is difficult to measure the heat transfer area of the target human body every time the thermal environment is evaluated. Therefore, formulas for calculating the body surface area, which is the heat transfer area, have been proposed for each stratum, such as age, for cases when the naked body condition is used as a reference. However, since it is difficult to determine the heat transfer area in the clothed state, the thermal environment evaluation index is usually calculated using the coefficient value of the increase rate of the heat transfer area for the naked body, assuming a typical combination of clothing.

The heat transfer area in the clothed state is obtained by multiplying the heat transfer area for the naked body by a coefficient value. This coefficient value is illustrated as clothing area factors for typical clothed combinations in the ASHRAE Fundamentals Handbook [1], for example. The coefficient values illustrated are a comprehensive list of previous research results. Studies on clothing area factor have used a photo method and a method of measuring the area of unfolded clothing. These coefficient values have been measured in the process of research to determine the thermal insulation of clothing, and there are few studies on the clothing area factor alone.

The photo method includes methods based on projection area using ordinary photographic lenses [2]-[13] and those based on projection area using orthographic fisheye lenses [14] [15] [16]. The methods for measuring the area of clothing include one based on an expansion plan view of the clothing [8] [17] and another taking into account the area and how the clothing overlaps through an expansion plan view of the clothing [18] [19].

For methods that do not involve actual measurements, the clothing area factor is calculated using a formula expressed as a linear equation in which the thermal insulation of clothing is an explanatory variable, as in the work of Sprague and Munson [4], Olesen et al. [5], Mcllough et al. [6], IOS 15831:2004 [20], and ISO 9920:2007 [21]. The calculation equation [14], expressed as a linear equation in which the air volume of the under-clothing climate related to the degree of clothing slack is an explanatory variable, is also used to determine the clothing area factor. The data on the clothing area factor on which these formulas are based are rooted in a photographic method in which the photographic projection image of the whole body is regarded as front-back and left-right symmetric$\mathrm{al}$, and is limited to only one side of the whole body, front-back or left-right. This factor may be limited to a standing posture. However, Yamato et al. [9] [10] 
and Kurazumi et al. [11] show the necessity of taking actual measurements over the entire circumference of the body when posture is considered.

Tomita et al. [8], Kakitsuba et al. [14], Kakitsuba and Suzuki [15], and Miyamoto and Tomita [16] present a clothing area factor with respect to radiation. Kakitsuba and Suzuki [15] show that the clothing area factor given by a linear equation using the thermal insulation of clothing is different from that for radiation. Tomita et al. [8] show that the clothing area factor given by the clothing expansion area is different from that for radiation. Kurazumi et al. [22] [23] [24] measured the heat transfer area due to convection and clarify the difference between that and the heat transfer area due to radiation, and it is inferred that similar data can be obtained for the clothing area factor.

While it is believed that clothing ease or slack affects the clothing area factor, Kurazumi et al. [11] clarifies the effect of changes in the air layer within clothing due to posture on the clothing area factor. Changes in the surface properties of clothing due to folding and overlapping and changes in the air layer in the space inside clothing are considered to have an effect, and differences in posture are believed to be strongly represented in the clothing area factor. The conventional formula for calculating the clothing area factor is considered unable to express the effect of posture.

Previous studies of the clothing area factor have almost always involved adults and extremely rarely have targeted infants. Compared to healthy individuals and adults, infants are less able to thermally adapt to their environment. In addition, it has not been measured by the actual infant human body. The outdoor environment during the summer season is a severe environment from the perspective of body temperature regulation, and it is considered necessary to take protective measures against the thermal environment. An infant's body tends to easily warm up in a hot environment and cool down in a cold environment [25]. Therefore, infants are thought to have different adaptations and sensory perceptions of their environment than adults [25] [26]. Compared to adults, infants have an extremely small body surface area but an extremely large body surface area per unit of body weight. Therefore, heat transfer is important for body temperature regulation [27].

As above mentioned, compare to adults, infants have less heat transfer involved in thermoregulation than adults [28] [29] [30] [31] [32]. Since infants have underdeveloped thermoregulation and low thermal adaptability, it is thought that attention to their bodies is necessary [33]. Infants differ from adults in terms of thermal environment and body temperature regulation, and it is therefore necessary to evaluate the thermal environment for infants. However, it is not ethical to conduct experiments on infants regarding the thermal environment based on body heat balance. Therefore, to examine the thermal environment of infants, experiments and simulations using a human body thermal model may be feasible by clarifying the human body coefficient values of infants. From this perspective, Kurazumi et al. [34] developed a thermal manikin of an 
infant based on heat transfer area. However, sufficient analysis and countermeasures are not yet developed.

Focusing on the heat transfer area of infants, a reference body surface area of infants has been measured [35]-[43]. Also, the solar radiation area factor of infants has been measured [44]. However, there are few studies on the heat transfer area of infants. Therefore, the purpose of this study was to clarify by actual measurements the clothing area factor for infants according to typical seasonal clothing combinations.

\section{Measurement Plan}

First, although the target of measurements should be healthy infants, it is ethically impossible and practically difficult to perform actual measurements, so a human infant body model was used as the target. Given that it is used in the medical and nursing fields, a Nurse Training Baby (3B Scientific: W17002, Asian Body Care Model male) manufactured by Nihon 3B Scientific Inc. [45] was used for the infant model, as shown in Figure 1.

The Nurse Training Baby is modeled on a donated body and consists of a head and neck, trunk (including gluteal region), arms, and legs. It is about 50 $60 \mathrm{~cm}$ in length. From the Growth Survey of Male Infants of the Ministry of Health, Labour and Welfare of Japan [46], the $50^{\text {th }}$ percentile data for the age of 1 to 2 months were extracted, giving a height of $55.6 \mathrm{~cm}$ and weight of $4.79 \mathrm{~kg}$. Kurazumi et al. [34] compared the body surface area calculated from height and weight data [36] [37] [39] [40] [47] [48] [49] with the measured body surface area of the infant model and clarified its validity as an infant model. The body surface area of each part of the infant model [34] is shown in Table 1.

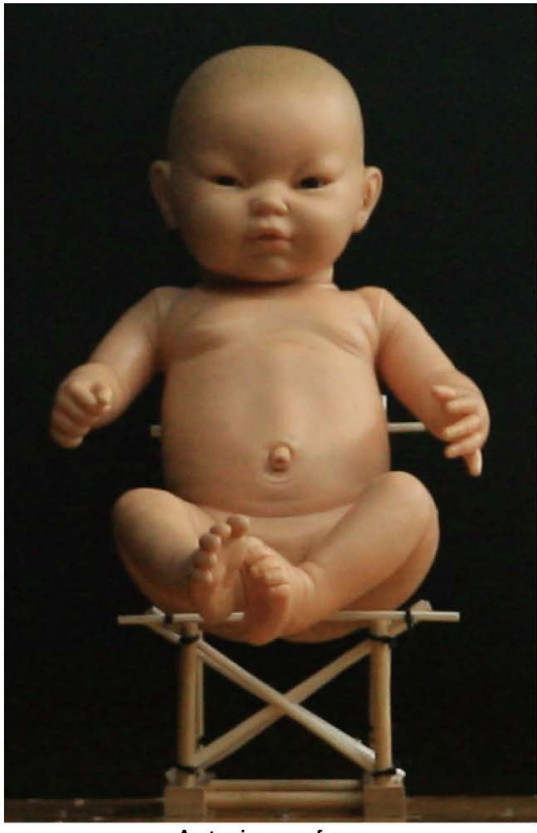

Anterior surface

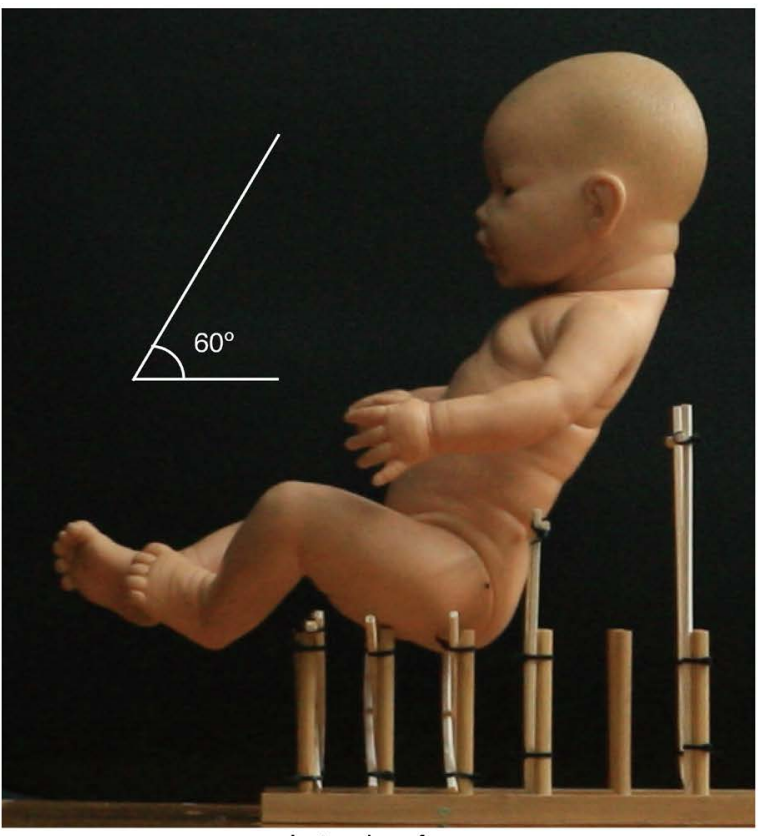

Lateral surface

Figure 1. Infant model. 
The combinations of infant clothing by season are shown in Figure 2. Table 2 shows the characteristics of the clothing. When dressing the infant model, sufficient care was taken to avoid uneven distribution of folds and overlaps due to wrinkles on the surface. The wrinkles, folds, and overlaps of the clothing that

Table 1. Profile of infant model.

\begin{tabular}{|c|c|c|c|}
\hline Reagion & Surface area $\left[\mathrm{cm}^{2}\right]$ & Area ratio [-] & Area ratio [-] \\
\hline Right head & 256.29 & 0.123 & 0.238 \\
\hline Left head & 240.53 & 0.115 & \\
\hline Right ventral trunk & 155.25 & 0.074 & 0.302 \\
\hline Left ventral trunk & 151.31 & 0.073 & \\
\hline Right dorsal trunk & 154.99 & 0.074 & \\
\hline Left dorsal trunk & 168.01 & 0.081 & \\
\hline Right upper arm & 61.66 & 0.030 & 0.117 \\
\hline Left upper arm & 60.71 & 0.029 & \\
\hline Right forearm & 59.61 & 0.029 & \\
\hline Left forearm & 60.87 & 0.029 & \\
\hline Right hand & 34.80 & 0.017 & 0.041 \\
\hline Left hand & 49.03 & 0.024 & \\
\hline Right thigh & 146.78 & 0.070 & 0.240 \\
\hline Left thigh & 159.07 & 0.076 & \\
\hline Right leg & 91.86 & 0.044 & \\
\hline Left leg & 105.32 & 0.050 & \\
\hline Right foot & 67.78 & 0.032 & 0.062 \\
\hline Left foot & 63.63 & 0.030 & \\
\hline
\end{tabular}
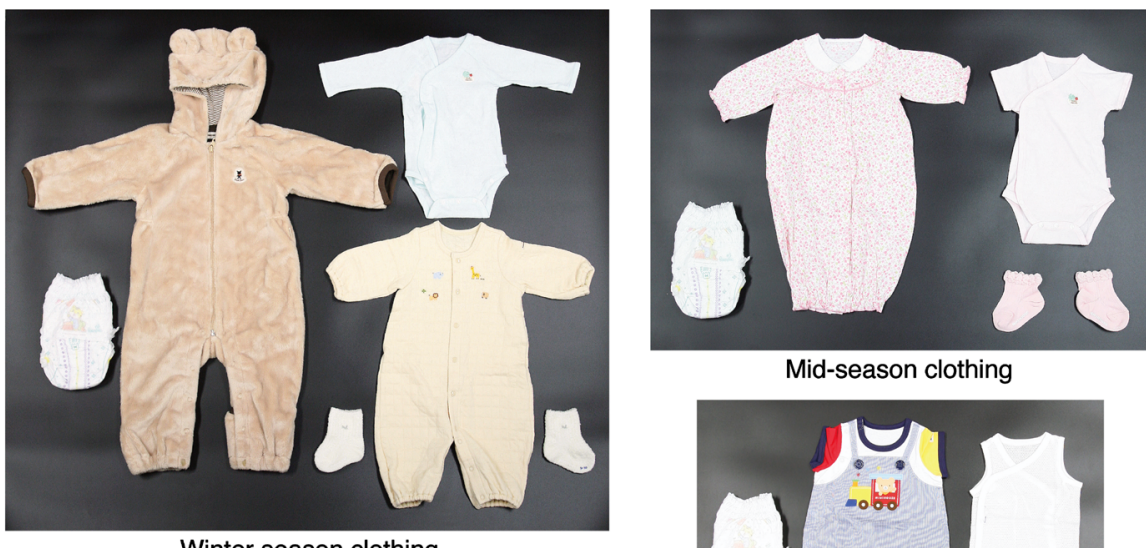

Mid-season clothing

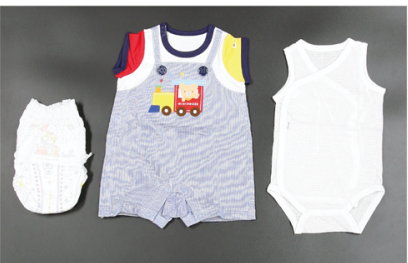

Summer season clothing

Figure 2. Seasonal clothing ensembles. 
Table 2. Profile of seasonal clothing ensembles.

\begin{tabular}{|c|c|c|c|c|}
\hline Description & Detail & Material (\%) & Weight $[\mathrm{g}]$ & Remark \\
\hline \multicolumn{5}{|l|}{ Summer season } \\
\hline Diaper & & & 25 & Pampers swaddlers, 0 - 3 months \\
\hline Underwear & Sleeveless rompers & Mesh Tenjik cotton (100) & 31 & miki house, 0 - 3 months, $60 \mathrm{~cm}$ \\
\hline Short coverall & Short sleeve T-shirt and rompers & Cotton (100) & 73 & miki house, 0 - 3 months, $60 \mathrm{~cm}$ \\
\hline \multicolumn{5}{|l|}{ Mid-season } \\
\hline \multicolumn{5}{|l|}{ Description } \\
\hline Diaper & & & 25 & Pampers swaddlers, 0 - 3 months \\
\hline Underwear & Short sleeve rompers & Milling cotton (100) & 43 & miki house, 0 - 3 months, $60 \mathrm{~cm}$ \\
\hline Two-way coverall & Long sleeve rompers & Cotton (100) & 92 & miki house, 0 - 3 months, $50-60 \mathrm{~cm}$ \\
\hline \multirow[t]{3}{*}{ Socks } & & Cotton (83) & 13 & miki house, 0 - 3 months, $9-10 \mathrm{~cm}$ \\
\hline & & Nylon (16) & & \\
\hline & & Polyurethane (1) & & \\
\hline \multicolumn{5}{|l|}{ Winter season } \\
\hline Diaper & & & 25 & Pampers swaddlers, 0 - 3 months \\
\hline Underwear & Long sleeve rompers & Milling cotton (100) & 48 & miki house, 0 - 3 months, $60 \mathrm{~cm}$ \\
\hline Two-way coverall & Long sleeve rompers & Cotton (100) & 133 & miki house, 0 - 3 months, $50-60 \mathrm{~cm}$ \\
\hline \multirow[t]{2}{*}{ Coverall } & Long sleeve rompers & Front fablic: polyester (100) & 431 & miki house, 0 - 3 months, $60-80 \mathrm{~cm}$ \\
\hline & & Back fablic: Cotton (100) & & \\
\hline \multirow[t]{4}{*}{ Socks } & & Acrylic (75) & 19 & miki house, 0 - 3 months, $9-10 \mathrm{~cm}$ \\
\hline & & Polyester (18) & & \\
\hline & & Nylon (5) & & \\
\hline & & Polyurethane (2) & & \\
\hline
\end{tabular}

occur when the infant model is moved to the set posture were assumed to be natural.

The actual measurement of the infant clothing area factor according to seasonal clothing combinations was carried out using the methods of Yamato et al. [9] [10] and Kurazumi et al. [11], which are modifications of the photographic method of Olesen et al. [5]. Olesen et al. [5] consider the photographic projection image of the whole body to be front-back and left-right symmetrical for the calculation of the clothing area factor, and they consider measurement by photography limited to only one side of the whole body, front-back or left-right, to be sufficient. The rationale for this is that Fanger et al. [50] assume that the standing human body is symmetrical and that the projection area from a point-symmetrical position centered on the human body is equal. However, Yamato et al. [9] [10] and Kurazumi et al. [11] measured the clothing area factor by posture and found left-right and front-back differences in the clothing area factor. Therefore, it is essential to measure the clothing area factor at all azimuth 
angles and different elevation angles for postures such as chair seated, leg-out seated, and seated in a buggy, in which a part of the body protrudes in the sagittal direction and is asymmetrical with respect to the coronal and median planes, and the body axis is vertical.

The actual measurement coordinate system is shown in Figure 3. The origin of the measurement coordinates was $0.05 \mathrm{~m}$ behind the umbilicus, which is the center point of the infant's body. Forty-eight points were measured using a combination of elevation and orientation angles. The elevation direction was made $0^{\circ}$ and $60^{\circ}$ from the coordinate origin. The infant model is not left-right symmetrical, and considering the established postures, the measured azimuth angles were set at $15^{\circ}$ intervals based on the median plane to enclose the infant model. A turntable mount similar to that of Tsuchikawa et al. [44] was used for the actual measurements of the photographic method.

A full-size digital camera (Canon: EOS 5D, Canon: EF24-70 mm f/2.8) was used for photography. The focal length of the lens was fixed at $70 \mathrm{~mm}$ for the measurements. In the photographic method, the distance from the subject to the camera station must be as long as possible to minimize the shooting error. Therefore, in this study, the measurement distance was determined based on the relative size of the subject (infant model) and an examination of the error caused by prior measurement of the projection area. As in Tsuchikawa et al.'s study [44], the measurement distance was set to $6.0 \mathrm{~m}$, at which the projection area error was $1 \%$ or less in the measurements.

To calculate the projection area of the subject in the captured image, a square piece of colored paper with a side of $0.15 \mathrm{~m}$ was placed next to the subject and photographed together with the subject, thereby forming a reference area facing the normal vector plane of the shooting elevation angle. Image processing software (Adobe: Photoshop CS6) was used to calculate the projection area. The extracted area of the infant body model was obtained by applying a coloring process to the captured images. The area of the infant model and the clothed part were measured, and the projection area was calculated based on the projection area of the $0.15-\mathrm{m}$ square in the same image. The clothing area factor at each measurement point was calculated by dividing the projection area of the
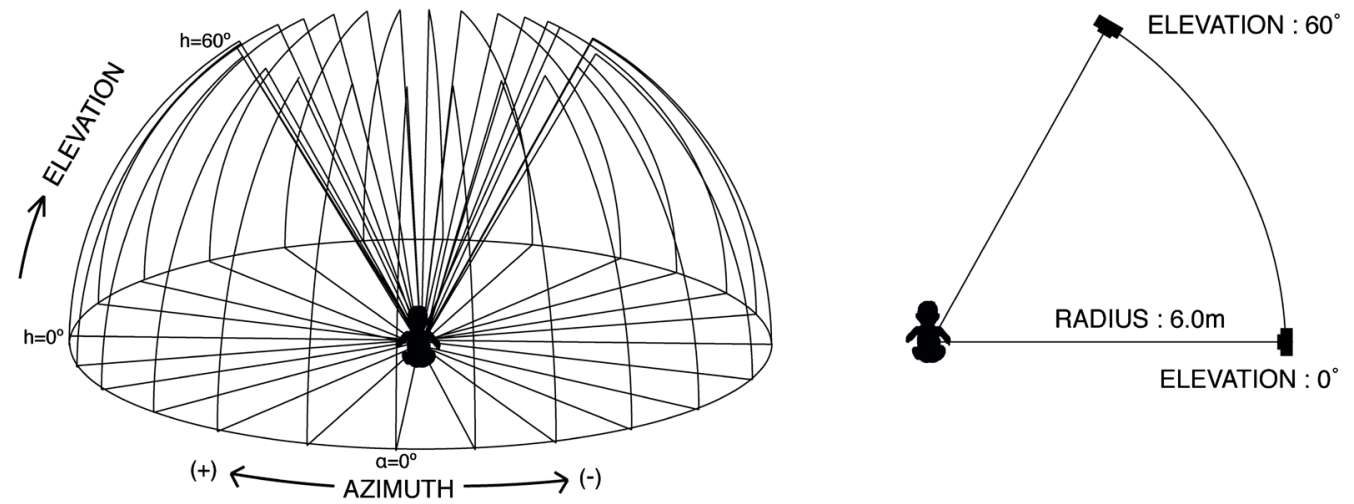

Figure 3. Coordinate system for measurement of clothing area factor. 
infant model when clothed by the projection area of the infant model when naked. To calculate the clothing area factor of the whole body, the calculation method of ISO 9920:2007 [21] was extended to the actual measurement points surrounding the whole body, and the clothing area factor of each measurement point was averaged. In this study, the significance probability was considered to be 5\%. JMP 14 (SAS Institute Japan) was used for statistical analysis.

\section{Results and Discussion}

Figure 4 shows the results of image processing for each orientation angle and elevation of the measured images. The area in red indicates the skin surface. The area in green indicates the surface of the clothing. The calculation results of the clothing area projection ratio of the infant body model are shown in Table 3. The change in the clothing area factor by azimuth angle showed a similar tendency to that of summer clothing, which tends to adhere to the body surface, for both elevation angles. The degree of change was greatest for winter clothing, followed by mid-season clothing. As the amount of overlapping clothing increased, the change in surface properties and the change in air volume in the clothing space due to folding and overlapping of the clothing also increased; this is thought to have affected the amount of change in the clothing area factor. The results are similar to those of Yamato et al. [9] and Kurazumi et al. [11], who examined the relationship between the sagittal plane left-right and coronal plane front-back azimuth angles of the human body and the clothing area factor. Kurazumi et al. [11] also found that in the leg-out seated position, in which the lower limb protrudes from the coronal plane, the clothing area factor was greater when the elevation angle was $60^{\circ}$ than when it was $0^{\circ}$. These results are consistent with the findings of this study. The mean value of the clothing area factor for each season was 1.22 for summer clothing, 1.42 for mid-season clothing, and 1.90 for winter clothing.

Kakitsuba and Suzuki [15] focus on clothing ease and show that the clothing area factor was affected by the air volume under the clothing. Kurazumi et al. [11] focus on differences in posture and show that the clothing area factor was affected by changes in the surface properties of the clothing due to folding and overlapping of the clothing and changes in the air layer of the space inside the clothing. Yamato et al. [10] focus on posture and clothing size and show that the clothing area factor was similar to the factor identified by Kurazumi et al. [11] and Kakitsuba and Suzuki [13]. The results of the present study were also consistent with the findings of Yamata et al. [10], Kurazumi et al. [11], and Kakitsuba and Suzuki [15].

The results of comparing the effect of seasonal clothing on the clothing area factor by ANOVA were $\mathrm{p}<0.01(\mathrm{RMSE}=0.08, \mathrm{~F}[2,149]=913.92, \mathrm{p}<0.01)$, showing a significant difference in the clothing area factor by season and indicating that differences in seasonal clothing strongly affect the clothing area factor. Furthermore, the results of a Tukey test showed $\mathrm{p}<0.01$ for summer and 


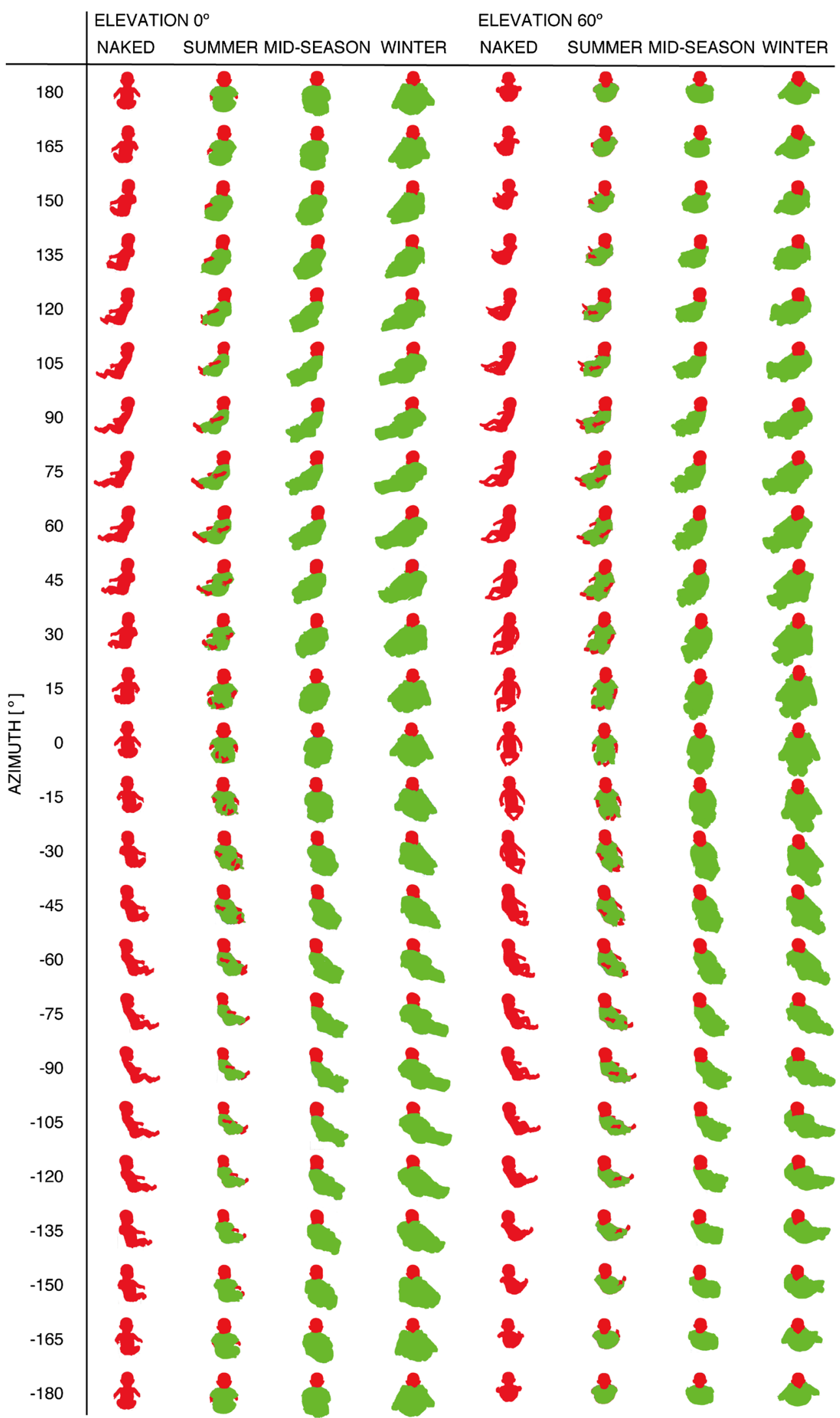

Figure 4. Results of measurement projection image processing. Red parts indicate the skin surface. Green parts indicate the clothing surface. 
Table 3. Result of clothing area factors.

\begin{tabular}{|c|c|c|c|c|c|c|}
\hline Azimuth $\left[{ }^{\circ}\right]$ & $\begin{array}{c}\text { Summer } \\
\text { Elevation } 0^{\circ}\end{array}$ & $\begin{array}{c}\text { Summer } \\
\text { Elevation } 60^{\circ}\end{array}$ & $\begin{array}{l}\text { Mid-season } \\
\text { Elevation } 0^{\circ}\end{array}$ & $\begin{array}{c}\text { Mid-season } \\
\text { Elevation } 60^{\circ}\end{array}$ & $\begin{array}{c}\text { Winter } \\
\text { Elevation } 0^{\circ}\end{array}$ & $\begin{array}{c}\text { Winter } \\
\text { Elevation } 60^{\circ}\end{array}$ \\
\hline-180 & 1.27 & 1.14 & 1.48 & 1.34 & 1.93 & 1.74 \\
\hline-165 & 1.26 & 1.17 & 1.45 & 1.39 & 1.93 & 1.76 \\
\hline-150 & 1.28 & 1.19 & 1.39 & 1.42 & 1.93 & 1.79 \\
\hline-135 & 1.26 & 1.19 & 1.34 & 1.42 & 1.89 & 1.84 \\
\hline-120 & 1.27 & 1.17 & 1.37 & 1.43 & 1.90 & 1.94 \\
\hline-105 & 1.27 & 1.17 & 1.40 & 1.44 & 1.95 & 1.91 \\
\hline-90 & 1.33 & 1.17 & 1.45 & 1.46 & 2.06 & 1.88 \\
\hline-75 & 1.29 & 1.15 & 1.43 & 1.45 & 1.94 & 1.74 \\
\hline-60 & 1.27 & 1.10 & 1.44 & 1.44 & 1.82 & 1.72 \\
\hline-45 & 1.24 & 1.10 & 1.45 & 1.45 & 1.74 & 1.74 \\
\hline-30 & 1.26 & 1.13 & 1.54 & 1.50 & 1.83 & 1.85 \\
\hline-15 & 1.28 & 1.16 & 1.56 & 1.52 & 1.94 & 1.98 \\
\hline 0 & 1.20 & 1.20 & 1.47 & 1.57 & 1.86 & 2.08 \\
\hline 15 & 1.31 & 1.17 & 1.56 & 1.48 & 2.09 & 2.07 \\
\hline 30 & 1.30 & 1.15 & 1.46 & 1.42 & 2.04 & 2.04 \\
\hline 45 & 1.27 & 1.17 & 1.38 & 1.42 & 1.95 & 2.02 \\
\hline 60 & 1.24 & 1.18 & 1.38 & 1.36 & 1.91 & 2.00 \\
\hline 75 & 1.25 & 1.17 & 1.39 & 1.34 & 1.96 & 1.99 \\
\hline 90 & 1.29 & 1.19 & 1.44 & 1.31 & 2.07 & 1.98 \\
\hline 105 & 1.28 & 1.20 & 1.43 & 1.32 & 1.95 & 2.01 \\
\hline 120 & 1.23 & 1.21 & 1.38 & 1.35 & 1.79 & 1.99 \\
\hline 135 & 1.25 & 1.21 & 1.43 & 1.37 & 1.73 & 1.88 \\
\hline 150 & 1.25 & 1.16 & 1.46 & 1.29 & 1.74 & 1.72 \\
\hline 165 & 1.24 & 1.18 & 1.47 & 1.33 & 1.83 & 1.78 \\
\hline 180 & 1.27 & 1.14 & 1.48 & 1.34 & 1.93 & 1.74 \\
\hline $\mathrm{fcl}[-]$ & \multicolumn{2}{|c|}{ Summer 1.22} & \multicolumn{2}{|c|}{ Mid-season 1.42} & \multicolumn{2}{|c|}{ Winter 1.90} \\
\hline
\end{tabular}

mid-season, summer and winter, and mid-season and winter, indicating a strong influence of seasonal clothing on the clothing area factor.

Looking at the seasonal clothing in this study in terms of the amount of ease, it can be assumed that summer clothing has the least and winter clothing has the most. Yamato et al. [10] and Kakitsuba and Suzuki [15] mention the relationship between clothing ease and clothing area factor. In addition, Yamato et al. [10] shows the relationship between posture and ease of clothing and found that the more ease the clothing has, the higher the clothing area factor in the case of postures such as chair seated and leg-out seated position. The results are consistent with these studies [10] [15]. 
According to the ASHRAE Fundamentals Handbook [1], the clothing area factor for the combination of insulated coverall with long-sleeved thermal underwear and long underwear bottoms, which approximates the winter clothing of infants, is 1.26. The clothing area factor for the combination of overalls with long-sleeved shirt and T-shirt, which approximates the clothing of the mid-season, is 1.27. The clothing area factor for the combination of walking shorts and short-sleeved shirt, which approximates summer clothing, is 1.10. The clothing area factor for the combination of knee-length skirt, which has a large degree of ease, with long-sleeved shirt, suit jacket, and panty hose is 1.46. Partly because of the standing posture, the value of the clothing area factor is low. The clothing area factor of infants is significantly greater than for adults.

Fukazawa et al. [13] measured the clothing area factor of 6 - 12-month-old infants using the simplified method of a standing position [12]. The clothing area factor for the combination of short sleeves with T-shirt and short trousers in summer ranged from 1.15 to 1.46 , with a mean value of 1.24 . The clothing area factor for the combination of undershirt with socks, sweatshirt, and thin trousers in the mid-season ranged from 1.04 to 1.39 , with a mean value of 1.18. The clothing area factor for the combination of undershirt with socks, long sleeve shirt, vest, jumper, and thick trousers in winter ranged from 1.16 to 1.42 , with a mean value of 1.29. The clothing area factor of infants in the present study was not significantly different from the clothing area factor of infants in the summer in Fukazawa et al's study [13], but it was significantly greater in the mid-season and winter, when thicker clothing was worn. From the Growth Survey of Infants of the Ministry of Health, Labour and Welfare of Japan [46], the $50^{\text {th }}$ percentile data for the age of 6 to 12 months was extracted, giving a height of 67.9 to $73.8 \mathrm{~cm}$ and weight of 8.0 to $9.1 \mathrm{~kg}$. The degree of growth and the degree of clothing fit may have an effect, but as Kurazumi et al. [11] point out, the clothing area factor is considered to be greater in the posture set in the present study, in which the lower extremities protrude from the coronal plane compared to the standing posture.

As described in the introduction, an infant's body tends to easily warm up in a hot environment and cool down in a cold environment [25]. Normally, infants' clothing is slightly large and has a lot of ease. The seasonal clothing determined in this study is useful data for examining the thermal environment of infants.

\section{Conclusion}

To clarify the clothing area factor of infants, the clothing area factor of an infant model clothed in typical summer, mid-season, and winter clothing was measured using a photographic method. The clothing area factor in each season was $1.22,1.42$, and 1.90 for summer, mid-season, and winter clothing, respectively, indicating a significant seasonal difference. It was also found that the clothing area factor was significantly greater for infants than for adults. When designing and evaluating the thermal environment for infants, it is essential to investigate 
using data from infants.

\section{Acknowledgements}

We would like to express our sincere gratitude to those who participated in this research. This work was supported by JSPS KAKENHI Grant Number JP18H01594.

\section{Conflicts of Interest}

The authors declare no conflicts of interest regarding the publication of this paper.

\section{References}

[1] ASHRAE (2017) 2017 ASHRAE Handbook Fundamentals, Chapter 8 Thermal Comfort. American Society of Heating, Refrigerating, and Air-Conditioning Engineers, Atlanta.

[2] Fanger, P.O. (1970) Thermal Comfort. Danish Technical Press, Copenhagen.

[3] Seppanen, O., McNall, P.E., Munson, D.M. and Sprague, C.H. (1972) Thermal Insulating for Typical Indoor Clothing Ensembles. ASHRAE Transactions, 78, 120-130.

[4] Sprague, C.H. and Munson, D.M. (1974) A Composite Ensemble Method for Estimating Thermal Insulating Values of Clothing. ASHRAE Transactions, 80, 120-129.

[5] Olesen, B.W., Silwinska, E., Madsen, T.L. and Fanger, P.O. (1982) Effect of Body Posture and Activity on the Thermal Insulation of Clothing; Measurements by a Movable Thermal Manikin. ASHRAE Transactions, 88, 791-805.

[6] Mcllough, E.A., Jones, B.W. and Zbikowski, P.J. (1983) The Effect of Garment Design on the Thermal Insulation Values of Clothing. ASHRAE Transactions, 89, 327-353.

[7] Mcllough, E.A., Jones, B.W. and Huck, J. (1985) A Comprehensive Data Base for Estimating Clothing Insulation. ASHRAE Transactions, 91, 29-47.

[8] Tomitra, A., Miyamoto, S. and Horikoshi, T. (1998) The Influence of Clothing Ease on the Projected Area of the Human Body at Standing Posture. Summaries of Technical Papers of Annual Meeting 1998 of Architectural Institute of Japan, Fukuoka, 11-13 September 1998, 409-410.

[9] Yamato,Y., Kurazumi, Y., Hashida, M., Torii, T. and Matsubara, N. (2003) Difference of Postures on Thermal Insulation of Clothing Ensembles. Journal of Human and Living Environment, 10, 108-116.

[10] Yamato, Y., Kurazumi, Y., Ishii, J., Fukagawa, K., Tobita, K., Matsubara, N. and Shibata, Y. (2010) The Influence of Extra Space of Clothing for Human Body on Thermal Insulation of Clothing Ensembles, Experimental Study on Woman's Clothes. Journal of the Japan Research Association for Textile End-Uses, 51, 281-292.

[11] Kurazumi, Y., Horiguchi, A., Sakamoto, H. and Matsubara, N. (2006) The Influence of Postures on Thermal Insulation of Clothing. Journal of Environmental Engineering ( Transactions of AI), 605, 63-70. https://doi.org/10.3130/aije.71.63 3

[12] Ueno, S. and Sawada, S. (2008) Measurement of the Thermal Resistance of Firefighters' Protective Clothing Using a Movable Thermal Manikin. Journal of Occupational Safety and Health, 1, 189-196. https://doi.org/10.2486/josh.1.189

[13] Fukazawa, T., Ikeda, S., Kim, S. and Tochihara, Y. (2009) Seasonal Clothing Variation and Thermal Resistance of Clothing Ensembles of Infants Living in Kyushu. Journal of Home Economics of Japan, 60, 635-643. 
[14] Kakitsuba, N., Michna, H. and Mekjavic, I.B. (1987) Clothing Surface Area as Related to Body Volume and Clothing Microenvironment Volume. Aviation, Space, and Environmental Medicine, 58, 411-416.

[15] Kakitsuba, N. and Suzuki, K. (1997) The Effect of Clothing Fit on Clothing Area Factor. Journal of Architecture, Planning and Environmental Engineering (Transactions of A.I.J.), 500, 37-41. https://doi.org/10.3130/aija.62.37 5

[16] Miyamoto, S. and Tomita, A. (2000) Examination of Quantitative Grasp of Clothing Thermal Insulation on Thermal Environmental Factor: An Increase at Effective Radiation Area Factor by Clothes. Proceedings of Tokai Chapter Architectural Research Meeting of Architectural Institute of Japan, 38, 537-540.

[17] Sakoi, T., Mochida, T., Nagano, K. and Shimakura, K. (2000) Fundamental Study on Evaluation of Clothing Thermal Insulation. Transactions of the Society of Heating, Air-Conditioning and Sanitary Engineers of Japan, 77, 95-107.

[18] Watanabe, S., Uchida, H., Horikoshi, T., Tomita, A. and Ishii, J. (1999) The Influence of Air Temperature, Air Velocity and Clothing Ease on the Clothing Thermal Insulation. Summaries of Technical Papers of Annual Meeting 1999 of Architectural Institute of Japan, Higashihiroshima, 17-19 September 1999, 391-392.

[19] Watanabe, S., Yoneda, Y., Tomita, A. and Horikoshi, T. (2000) Effect of Air Velocity and Clothing Ease on Clo Value: Comparison of Calculation Methods for Clo Value. Proceedings of Tokai Chapter Architectural Research Meeting of Architectural Institute of Japan, 38, 541-544.

[20] ISO (2004) ISO 15831:2004 Clothing-Physiological Effects-Measurement of Thermal Insulation by Means of a Thermal Manikin. International Organization for Standardization, Geneva.

[21] ISO (2007) ISO 9920:2007 Ergonomics of Thermal Environment-Estimation of the Thermal Insulation and Evaporative Resistance of a Clothing Ensemble. International Organization for Standardization, Geneva.

[22] Kurazumi, Y., Tsuchikawa, T., Yamato, Y., Kakutani, K., Matsubara, N. and Horikoshi, T. (2003) The Posture and Effective Thermal Convection Area Factor of the Human Body. Japanese Journal of Biometeorology, 40, 3-13.

[23] Kurazumi, Y., Tsuchikawa, T., Matsubara, N. and Horikoshi, T. (2004) Convection Heat Transfer Area of the Human Body. European Journal of Applied Physiology, 93, 273-285. https://doi.org/10.1007/s00421-004-1207-1

[24] Kurazumi, Y., Tsuchikawa, T., Matsubara, N. and Horikoshi, T. (2008) Effect of Posture on the Heat Transfer Areas of the Human Body. Building and Environment, 43, 1555-1565. https://doi.org/10.1016/j.buildenv.2007.09.001

[25] Iriki, M. (1995) Taion cyosetu no shikumi. Bunkodo Co., Ltd., Tokyo. (In Japanese)

[26] Nakayama, A. and Iriki, M. (1987) Shin seirikagaku taikei 22, Enerugi taisya Taion cyosetu no seirigaku. Igaku-Shoin Ltd., Tokyo. (In Japanese)

[27] Bar-Or, O. (1980) Climate and the Exercising Child-A Review. International Journal of Sports Medicine, 1, 53-65. https://doi.org/10.1055/s-2008-1034631

[28] Wagner, J.A., Robinson, S. and Marino, R.P. (1974) Age and Temperature Regulation of Humans in Neutral and Cold Environments. Journal of Applied Physiology, 37, 562-565. https://doi.org/10.1152/jappl.1974.37.4.562

[29] Haymes, E.M., McGormick, R.J. and Buskirk, E.R. (1975) Heat Tolerance of Exercising Lean and Obese Prepubertal Boys. Journal of Applied Physiology, 39, 457-461. https://doi.org/10.1152/jappl.1975.39.3.457

[30] Drinkwater, B.L., Kupprat, I.C., Denton, J.E., Crist, J.L., Horvath, S.M. (1977) Re- 
sponse of Prepubertal Girls and College Women to Work in the Heat. Journal of Applied Physiology, 43, 1046-1053. https://doi.org/10.1152/jappl.1977.43.6.1046

[31] Araki, T., Toda, Y., Inoue, Y. and Tsujino, A. (1979) Age Differences in Sweating during Muscular Exercise. Journal of Physical Fitness and Sports Medicine, 28, 239-248. https://doi.org/10.7600/jspfsm1949.28.239

[32] Sugiura, H., Kinoshita, H. and Fujimoto, T. (2011) Questionnaire Investigation on the Infant's Sweat in Four Seasons. The Journal of Child Health, 70, 535-541.

[33] Tsuzuki, K., Ohnaka, T. and Tochihara, Y. (1998) Seasonal Variation and Age Difference in Thermal Responses under Preferred Temperatures Determined by the Mothers. Journal of Home Economics of Japan, 49, 1109-1117.

[34] Kurazumi, Y., Sakoi, T., Yamashita, K., Fukagawa, K., Kondo, E. and Tsuchikawa, T. (2019) Thermal Manikin of Infant. Engineering, 11, 735-754. https://doi.org/10.4236/eng.2019.1111048

[35] Meeh, K. (1879) Ober flächenmessungen des menschlichen körpers. Zeitschrift für Biologie, 15, 425-458.

[36] Lissauer, W. (1903) Ueber oberflächenmessungen un säuglingen und ihre bedeutung für den nahrungsbedarf. Jahrbuch für Kinderheilkunde und Physische Erziehung. N.F., 58, 392-411.

[37] Lassabliére, P. (1910) Evaluation de la surface cutanée chez le jeune enfant. Comptes rendus hebdomadaires des séances et mémoires de la société de biologie, 59, 339-341.

[38] Klein, A.D. and Scammon, R.E. (1930) The Regional Growth in Surface Area of the Human Body in Prenatal Life. Proceedings of the Society for Experimental Biology and Medicine, 27, 463-466. https://doi.org/10.3181/00379727-27-4809

[39] Otani, K. (1907) Nihon syoni no taihyo menseki sokutei. Tokyo igakkai zasshi, 21, 89-117. (In Japanese)

[40] Oshiro, C. and Tagawa, T. (1936) Nihon nyuji no taihyo menseki sokutei seiseki. Nika zasshi, 43, 604-616. (In Japanese)

[41] Ochi, T. and Higuchi, T. (1935) On the Body Surface Measurements and Normal Standard of Basal Metabolism of New Born Infants. Keio igaku, 15, 709-725. (In Japanese)

[42] Kawabata, M. (1940) Isshin taihyo menseki keisan shiki. Nihon seiri gakkai zasshi, 5, 245-254. (In Japanese)

[43] Miyajima, T. (1960) Nihon jin no taihyo menseki ni kansuru kenkyu, Dai 13 nyuji no taihyo menseki oyobi sono sansyutu shiki. Nagasaki sogo kosyu eiseigaku zasshi, 9, 484-499. (In Japanese)

[44] Tsuchikawa, T., Kondo, E. and Kurazumi, Y. (2019) Solar Radiation Area Factors of the Infant on Buggy. Journal of Human and Living Environment, 26, 87-92.

[45] Nihon 3B Scientific Inc. (2021) Nurse Training Baby, Asian Body Care Model Male, W17002. https://www.3bs.jp/simulator/child/w17002-w17003.htm

[46] Ministry of Health, Labour and Welfare, Japan (2021) National Growth Survey on Preschool Children. https://www.mhlw.go.jp/toukei/list/dl/73-22-01.pdf

[47] Boyd, E. and Scammon, R.E. (1930) The Relation of Surface Area Body Weight in Postnatal Life. Proceedings of the Society for Experimental Biology and Medicine, 27, 449-453. https://doi.org/10.3181/00379727-27-4804

[48] Kobayashi, O., Washio, S., Kodama, T., Sakaguchi, S. and Hayashi, I. (1952) Honpo syoni no taihyo menseki ni tuite. Nihon syonika gakkai zasshi, 56, 217-221. (In 
Japanese)

[49] Fujimoto, S., Watanabe, T., Sakamoto, A., Yukawa, K. and Morimoto, K. (1968) Studies on the Physical Surface Area of Japanese, Part 18 Calculation Formulas in Three Stages over All Age. Japanese Journal of Hygiene, 23, 443-450. https://doi.org/10.1265/jih.23.443

[50] Fanger, P.O., Angelius, O. and Jensen, P.K. (1970) Radiation Data for the Human Body. ASHRAE Transactions, 76-II, 338-373. 